\title{
Determination of the Suitability of Sand Deposits from River Yargamji for Making Container Glass
}

\author{
Muhammad Aminu, Muntari Abubakar, Lawal Alqasim, Saifullahi Sani
}

\begin{abstract}
Glass is a unique material that has been produced for thousands of years. The glass industry's products are an integral part of the world economy and everyday life. Glass products are used in food and beverage packaging, lighting, communications, transportation, and building construction. The purpose of this research work is to determine the suitability of sand deposits at River Yargamji for making container glass. The materials used were: sets of sieves, sieve shaker, EDXRF machine, Beakers, Weighing balance, Plastic containers, HCl and distilled water. The sand samples were obtained by hand digging with hoe and were collected from five different locations in the site, they were mixed thoroughly, divided into two and were labeled $A$ and $B$ respectively. The samples were washed with tap water until a clear water start flowing. Undiluted $\mathrm{HCl}$ acid was poured into sample $\mathrm{A}$, while, $50 \%$ by $50 \% \mathrm{HCl}$ and distilled water were mixed and poured into sample $B$, the mixtures were stirred simultaneously. After 25minutes, the mixtures were decanted and the samples were thoroughly washed with distilled water, then the samples were allowed to dry. Particle size analysis was determined by passing the material through a series of sieves stacked with progressively smaller openings from top to bottom and weighing the material retained on each sieve. X-Ray Fluorescence (XRF) Analysis was used to carry out the chemical analysis of the samples and the results were tabulated. Batch was calculated and formulated. The results shows that the sand deposits is suitable for glass making due to their high $\mathrm{SiO} 2$ content and low $\mathrm{Fe} 2 \mathrm{O} 3$ content coupled with suitable grain size distribution fractions. The sand deposits in Katsina is recommended for the production of glasses such as container, float, windscreen, fluorescent tubes, etc. because the sand contain high percentage of $\mathrm{SiO} 2$, it also yielded a clear glass.
\end{abstract}

Index Terms - Container Glass, Chemical Analysis, Glassmaking Oxides, Particle Size Distribution, Silica sand.

\section{INTRODUCTION}

Glass is a unique material that has been produced for thousands of years. The glass industry's products are an integral part of the world economy and everyday life. Glass products are used in food and beverage packaging, lighting, communications, transportation, and building construction [1].

\footnotetext{
Muhammad Aminu, Department of Basic and Applied Sciences, College of Science and Technology, Hassan Usman Katsina Polytechnic, Katsina State, Nigeria

Muntari Abubakar, Department of Basic and Applied Sciences, College of Science and Technology, Hassan Usman Katsina Polytechnic, Katsina State, Nigeria

Lawal Alqasim, Department of Basic and Applied Sciences, College of Science and Technology, Hassan Usman Katsina Polytechnic, Katsina State, Nigeria

Saifullahi Sani, Department of Basic and Applied Sciences, College of Science and Technology, Hassan Usman Katsina Polytechnic, Katsina State, Nigeria
}

Glass is a non-crystalline solid being usually transparent and has widespread practical, technological, and decorative usage in things like window panes, tableware, optoelectronics and etc. Scientifically, the term "glass" is often defined in a broader sense, encompassing every solid that possesses a non-crystalline structure (that is, amorphous) at the atomic scale and exhibits a glass transition when heated towards the liquid state [2].

Because of the fact that glass can be formed or moulded into any shape, and also because it is a sterile product, it has been traditionally used for vessels: bowls, vases, bottles, jars and drinking glasses. In its most solid forms it has also been used for paper weights, marbles, and beads. When extruded as glass fibre and matted as glass wool in a way to trap air, it becomes a thermal insulating material, and when these glass fibres are embedded into an organic polymer plastic, they are a key structural reinforcement part of the composite material fiberglass. Some objects are so commonly made of glass that they are simply called by the name of the material, such as drinking glasses and reading glasses [3].

The glass industry comprises five main sectors covering different glass products, applications and markets. These sectors are very different, whether in terms of manufacturing process, products, markets, the economics of the sectors and manufacturers but they all transform raw materials into glass by process of fusion (melting).

- Container glass provides a wide range of glass packaging products for food and beverages as well as flacons for perfumery, cosmetics and pharmaceutical products to a European and world-wide customer base.

- Flat glass is used in buildings (windows and facades) and automotive industries (windscreens, side and rear-side glazing, backlights and sunroofs). Flat glass is also used in solar-energy applications (photovoltaic and solar thermal panels) as well as in urban and domestic furniture, appliances, mirrors and greenhouses; almost all flat glass is made by means of the float process.

- Continuous filament glass fibre is mainly used for the production of composite materials as weight-lightening reinforcement components. Continuous filament glass fibre applications are known as fibre-reinforced polymers or glass-reinforced plastics. The sector covers applications for the automotive and transportation sectors (such as airplanes) as well as for many other sectors including wind energy, agriculture, construction, communication, and electrical and 
electronic goods.

- Domestic glass comprises the manufacturing of glass tableware, cookware and decorative items such as drinking glasses, bowls, plates, vases and ornaments.

- Special glass has a high added value linked to its intense technological content. This sector includes a large range of products such as lighting glass, glass tubes, laboratory glassware, glass ceramics, heat-resistant glass, optical and ophthalmic glass, extra thin glass for the electronics industry such as liquid crystal display (LCD) panels, photovoltaic and radiation protection glasses [4].

In the glass industry, the term container refers to glass packaging including bottles and jars through to customised glass packaging such as that used for the perfume industry.More than $95 \%$ of all manufactured container glass is made from sodium oxide $\left(\mathrm{Na}_{2} \mathrm{O}\right)$, calcium oxide $(\mathrm{CaO})$ and silicon dioxide $\left(\mathrm{SiO}_{2}\right)$, commonly known as a soda-lime silicateglass composition. Due to universal similarities in manufacturing techniques for glass containers, particularly the viscosity requirements of high speed "press and blow" production equipment, the chemical formulations of glass food and beverage containers have relative uniformity and compatibility. Container glass is formulated to set up quickly and to hold its shape when mechanically blown inside moulds. A random mix of container glasses is known to be relatively homogenous, provided there are no significant contamination levels [5].

The most familiar type of glass used for centuries as windows and container glass is the Soda-Lime Silica Glass with a typical composition of about $75 \%$ silica $\left(\mathrm{SiO}_{2}\right)$ from quartz or sandstone, soda $\left(\mathrm{Na}_{2} \mathrm{O}\right)$ from soda ash $\left(\mathrm{Na}_{2} \mathrm{CO}_{3}\right)$, lime $(\mathrm{CaO})$ from limestone $\left(\mathrm{CaCO}_{3}\right)$ and several other additives. Silica $\left(\mathrm{SiO}_{2}\right)$ is an acidic oxide, that is, it provides the acidic oxide in the glass. It is the fundamental constituent of all oxide glasses such as soda-lime silica glass, borosilicate glass, aluminosilicates glass, lead silicate glass and vitreous or fused silica glass. It occurs in nature both in its free state in form of quartz and in combined form (i.e. in its silicate form) [6].

\section{CONTAINER PRODUCTION}

Container glass are basically formed by blowing molten glass into a series of two different split moulds using either compressed air or mechanical pressing for shaping. This two-step process uses two different moulds:

- The blank mould, where pressing or blowing may be employed for shaping and

- The final blow mould.

The majority of container glass are manufactured using an automatic process known as I. S. Machine 'Individual Sections'. The whole process of container making can be simplified into the following main steps: Initially, a gob of glass is made by forming a portion of the glass melt from the furnace through an orifice ring where it is sheared to form a 'gather' or gob of glass which is subsequently manipulated to form the article. The gob is fed into a blank mould where the neck and preformed body of the container is formed. Ideally, the gob is supplied in an isothermal state with its viscosity high enough to prevent too rapid flow under gravity. The final container is then made using stage two of the process known as either 'blow and blow' or 'press and blow' methods [7].

The temperature of the molten glass is very important to the formation of gobs. If the glass is too cool, the melt is too viscous to transfer properly. Cooling systems may be employed to eliminate temperature variations in the gobs. The forehearth temperature is also carefully controlled for this reason.

Today nearly all container manufacturers use the IS (Individual Section) machine to automatically form containers from gobs. Each "Individual Section" of the machine contains its own set of moulds and is independent of the other sections. Any section of the machine may be shut down and be repaired or maintained without disruption of the other sections. The IS machine is capable of handling a variety of types and sizes of moulds, and can produce containers at rates of well over 100 per minute [8].

\section{StUdy AREA}

Katsina is one of the 36 States of the Federal Republic of Nigeria. It was created in 1987 from the defunct Kaduna State and is located between latitude $11008^{\prime}$ North and $13022^{\prime}$ North and longitude 60 52' East and 90 20' East. It covers a total area of approximately $23,983 \mathrm{sq} \mathrm{km}$. The State is bounded to the east by Kano and Jigawa States, to the West by Zamfara State, to the South by Kaduna State and to the North by Niger Republic [9]

In terms of physical settings, Katsina State has a Tropical Continental climate with high mean annual temperature over $27^{\circ} \mathrm{C}$, lower annual and single maxima rainfall [10]. The vegetation is Sudan Savanna type with short scattered trees, shrubs and grasses. The relief is made up of land between 399-600 meters above sea level [11].

The economy of the State is basically agrarian in nature with large percentage of the population involved in farming as full or part time occupation. The state is a major collection centre for cash crops such as cotton, ground-nuts and food crops such as maize, guinea corn, millet and vegetables [9].

Katsina is a mono ethnic and monolingual state and the people are generally Hausa/Fulani. The creation of Katsina State in 1987 brought with it the usual increase in the volume of economic and social activities attendant to a new state.

The mineral potentials of Katsina State are enormous, the national demand for industrial materials and associated products, as industrial input is very high. The part which the development of solid minerals can play in accelerating economic, political and social growth within the State or indeed the Nation is immerse, self-reliance in industrial minerals raw materials requirement, not only saves foreign exchange used in the importation of often over-priced and over specified materials, but also gives valuable technological job-training, provides gainful employment. Solid minerals can provide ultimate funds for investment in 
other sectors of the economy and generate foreign exchange for the Country. These metallic and nonmetallic mineral deposits that are found in the state include silica sand, kaolin, asbestos, gold, uranium, nickel and chromite.

\section{METHOD}

The sand samples were obtained by hand digging with hoe and were collected from five different locations in the river, they were mixed thoroughly, divided into two and were labeled A and B respectively.

Beneficiation was done in order to improve the quality of sand and also to minimize the presence of iron oxide $\left(\mathrm{Fe}_{2} \mathrm{O}_{3}\right)$ content in the samples. The samples were washed with tap water until a clear water start appearing. Concentrated $\mathrm{HCl}$ acid was poured into sample $\mathrm{A}$, while, $50 \%$ by $50 \% \mathrm{HCl}$ and distilled water were mixed and poured into sample $\mathrm{B}$, the mixtures were stirred simultaneously. After 25minutes, the mixtures were decanted and the samples were thoroughly washed with distilled water, then the samples were allowed to dry.

Aggregate gradation (sieve analysis) is the distribution of particle sizes expressed as a percent of the total dry weight. Gradation is determined by passing the material through a series of sieves stacked with progressively smaller openings from top to bottom and weighing the material retained on each sieve. According to Doyle, (1994) British Standard Specification (BS 2975) specified that the particle size requirement is that $80 \%$ of the sand grains should fall between 420microns (36 BS mesh) and 150microns (100 BS mesh). There should be nothing coarser than 1000microns (25 BS mesh).in the smaller particle size range, not more than $5 \%$ should be finer than 125 microns (120 BS mesh). A set of five Standard sieves were used, as shows in the table 1 below.

Sieve Series Width of Aperture.
\begin{tabular}{|c|c|}
$\begin{array}{c}\text { British Standard Sieve } \\
\text { Series Mesh No. }\end{array}$ & $\begin{array}{c}\text { Sieve Series Width of } \\
\text { Aperture. }\end{array}$ \\
\hline 16 & 1000 micron \\
\hline 25 & 600 micron \\
\hline 36 & 420 micron \\
\hline 100 & 150 micron \\
\hline 120 & 125 micron \\
\hline Pan & Submicron \\
\hline
\end{tabular}

The appropriate sieves in which the coarsest sieve, the uppermost grading down to the finest at the bottom with the receiver (or pan) at the bottom which collect the finest grains (submicron) were arranged. The dried sand sample was poured into the top sieve of the stacked set of sieves and covered with the lid. The sieve shaker machine sieves the sand sample for about 5 minutes. The sand retained on each of the sieves is measured digital balance and recorded in a sheet of paper. The procedures was repeated for the other sample, measured and recorded in each case.

\section{CHEMICAL ANALYSIS}

Energy Dispersive X-ray fluorescence (EDXRF) spectrometer of model "Minipal 4" was used for the analysis. $20 \mathrm{~g}$ of the prepared sample were weighed each into a sample cup. The cups with the contents were carefully placed in their respective measuring positions on a sample changer of the machine.

\section{RESULTS}

As mentioned earlier, particle size distribution analysis (sieving) is the separation of fine materials from coarse materials by means of a meshed or perforated surface. The results of the sieve analysis shows that the sand deposits contain high percentage of the particle size required for glassmaking, that is, the particle size for the samples are within the required range, as shown in the table below.

Table 1: Shows the BS Sieve Series Mesh Number and

Table 2: Results of Sieve Analysis of the Samples

\begin{tabular}{|l|l|l|l|l|}
\hline $\begin{array}{c}\text { Mesh aperture } \\
\text { (microns) }\end{array}$ & Sample A (g) & Percentage (\%) & Sample B (g) & Percentage (\%) \\
\hline 1000 & 9.03 & 4.515 & 8.67 & 4.335 \\
\hline 600 & 10.33 & 5.165 & 11.08 & 5.540 \\
\hline 420 & 61.75 & 30.875 & 60.68 & 30.340 \\
\hline 150 & 102.41 & 51.205 & 103.67 & 51.835 \\
\hline 125 & 11.28 & 5.640 & 10.35 & 5.175 \\
\hline Pan & 4.78 & 2.390 & 5.03 & 2.515 \\
\hline Lost & 0.42 & 0.210 & 0.52 & 0.260 \\
\hline
\end{tabular}

From the X-Ray Fluorescence Analysis carried out, the below results were obtained 
Table 3: XRF Analysis Results

\begin{tabular}{|l|l|l|}
\hline Oxide Composition (\%) & A, Conc. HCL & B, Dilute $\mathrm{HCl}$ \\
\hline $\mathrm{SiO}_{2}$ & 97.70 & 97.30 \\
\hline $\mathrm{Al}_{2} \mathrm{O}_{3}$ & 0.40 & 0.70 \\
\hline $\mathrm{Na}_{2} \mathrm{O}$ & 0.32 & 0.31 \\
\hline $\mathrm{K} 2 \mathrm{O}$ & 0.30 & 0.28 \\
\hline $\mathrm{CaO}$ & $\mathrm{ND}$ & $\mathrm{ND}$ \\
\hline $\mathrm{MgO}$ & $\mathrm{ND}$ & $\mathrm{ND}$ \\
\hline $\mathrm{TiO}_{2}$ & 0.37 & 0.17 \\
\hline $\mathrm{Cr}_{2} \mathrm{O}_{3}$ & $\mathrm{ND}$ & 0.024 \\
\hline $\mathrm{F}_{\mathrm{e} 2} \mathrm{O}_{3}$ & 0.40 & 0.51 \\
\hline $\mathrm{V}_{2} \mathrm{O}_{5}$ & $\mathrm{ND}$ & $\mathrm{ND}$ \\
\hline $\mathrm{Co}_{3} \mathrm{O}_{4}$ & 0.003 & 0.003 \\
\hline $\mathrm{CuO}^{\mathrm{GaO}}$ & 0.027 & 0.027 \\
\hline $\mathrm{Ga}_{2} \mathrm{O}_{3}$ & 0.006 & 0.006 \\
\hline $\mathrm{As}_{2} \mathrm{O}_{3}$ & 0.008 & 0.012 \\
\hline $\mathrm{SrO}$ & $\mathrm{ND}$ & 0.022 \\
\hline $\mathrm{ZrO}_{2}$ & 0.025 & $\mathrm{ND}$ \\
\hline $\mathrm{CeO}$ & 0.13 & 0.11 \\
\hline $\mathrm{BaO}$ & $\mathrm{ND}$ & 0.17 \\
\hline $\mathrm{PbO}$ & 0.018 & 0.51 \\
\hline $\mathrm{L} . \mathrm{O} . \mathrm{I}$ & 0.29 & \\
\hline
\end{tabular}

\section{$\mathrm{ND}=\mathrm{NOT}$ DETECTED}

\section{BATCH FORMULATION}

From the batch calculations of the analyzed samples, the result shown in the table below was obtained for container glass. For container glass, the amount of oxides required are $\mathrm{SiO}_{2}$ 75.00, $\mathrm{Al}_{2} \mathrm{O}_{3}$ 7.00, $\mathrm{Na}_{2} \mathrm{O}$ 16.0, $\mathrm{K}_{2} \mathrm{O}$ 3.00, $\mathrm{MgO}$ 5.00, $\mathrm{CaO} 12.00$ and $\mathrm{BaO} 0.50$ grams respectively. Raw oxides will be added in the batch so as to supplement for the incomplete oxides and those that were not detected by the XRF machine.

Table 4: Batch formulated for Container Glass

\begin{tabular}{|c|c|c|c|c|}
\hline $\begin{array}{c}\text { Sand } \\
\left(\mathrm{SiO}_{2}\right)\end{array}$ & $\mathrm{Al}_{2} \mathrm{O}_{3}$ & $\mathrm{Na}_{2} \mathrm{O}$ & $\mathrm{K}_{2} \mathrm{O}$ & $\mathrm{BaO}$ \\
\hline 77.08 & 0.53 & 0.23 & 0.21 & 0.08 \\
\hline
\end{tabular}

\section{TEST-MELTING}

The result of the test-melting is as shown in the figure below; a clear glass.

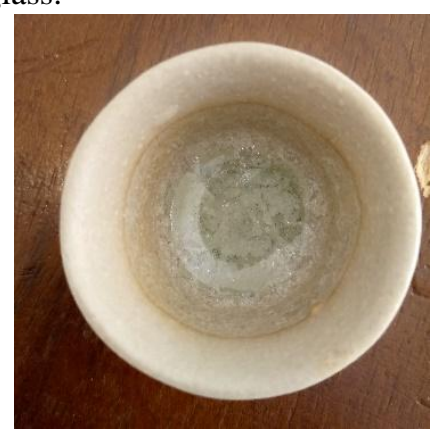

Figure 1: Melted Glass

\section{DISCUSSION}

The sieve analysis shows high percentage of particle size required for glass making within the range of 420 microns to 150 microns mesh size. This indicate that the sand deposit contains high amount of sand required for glass making in terms of particle size distribution as analyzed. Grain size distribution plays an important part in silica sand requirement. Large grain do not mixed proper with the other grains in the batch and causes stones in the glass final products while too fine grain create air bubble in the glass final product and also cause blockage to the furnace openings.

In the chemical analysis, several oxides were found in the samples, and some were not detected by the XRF machine. The elements that are not detected are $\mathrm{CaO}, \mathrm{MgO}, \mathrm{Cr}_{2} \mathrm{O}_{3}$, $\mathrm{V}_{2} \mathrm{O}_{5}, \mathrm{SrO}_{2}$ and $\mathrm{BaOin}$ sample $\mathrm{A}$, while $\mathrm{CaO}, \mathrm{MgO}, \mathrm{V}_{2} \mathrm{O}_{5}$ and $\mathrm{CeO}_{2}$ in sample $\mathrm{B}$. This was probably as a result of the reaction of the acid with the oxides. Moreover, some of the undetected oxides such as $\mathrm{Cr}_{2} \mathrm{O}_{3}$ add colour to the finished glass, therefore, they are unwanted for colourless glassware.

The test-melting yielded a clear glass that can be used in the production of container glasses such as bottles.

\section{CONCLUSION}

Analysis of the sand deposit revealed that the silica sand sample generally contain a high percentage concentration of silicon dioxide $\left(\mathrm{SiO}_{2}\right)$ content with significant amount of $\mathrm{Al}_{2} \mathrm{O}_{3}, \mathrm{~K}_{2} \mathrm{O}, \mathrm{Na}_{2} \mathrm{O}$, and trace amount of $\mathrm{Co}_{3} \mathrm{O}_{4}, \mathrm{CuO}, \mathrm{Ga}_{2} \mathrm{O}_{3}$, $\mathrm{As}_{2} \mathrm{O}_{3}, \mathrm{CeO}_{2}$ and $\mathrm{PbO}$. The grain size distribution of silica sand sample falls within the recommended screen size (425microns-150microns mesh). The beneficiated sand sample contains $97.70 \% \mathrm{SiO}_{2}$ and $0.40 \% \mathrm{Fe}_{2} \mathrm{O}_{5}$ for sample $\mathrm{A}$, while sample $\mathrm{B}$ contains $97.30 \% \mathrm{SiO}_{2}$ and $0.51 \% \mathrm{Fe}_{2} \mathrm{O}_{5}$.

These shows that the silica sand deposits are suitable for glass making due to their high $\mathrm{SiO}_{2}$ content and low $\mathrm{Fe}_{2} \mathrm{O}_{3}$ content coupled with suitable grain size distribution fraction.

\section{RECOMMENDATION}

Based on the findings and observations of this study, the following recommendations were made: 
- The sand deposits in Katsina state are recommended for the production of all types of soda-lime glasses such as container, float, windscreen, fluorescent tubes, etc. this is because of the fact that the sand contain high percentage of $\mathrm{SiO}_{2}$, it also yielded a clear glass.

- The Government should establish glass manufacturing industries in Katsina state so as to utilize the abundant raw materials which will serve as source of revenue to the Government and also to create more job opportunities to the people within the area and Nigeria at large.

- Establishing glass industries in Katsina state will equally check the activities of bandits in the area and in Nigeria at large by making their hideout to serve as the industrial sites.

\section{REFERENCES}

[1] Jamison. K, Eisenhauer. J and Rash. J (2002) Glass Industry Technology Roadmap. Glass Manufacturing Industry Council P.O. Box 6136 Westerville, OH 43086-6136 (614) 818-

[2] Karasu. B, Bereket. O, Biryan. E and Sanoglu. D (2017) The Latest Development in GlassScience and Technology. El-cezeri Journal of Science and Technology, Vol: 4 No: 2

[3] Scholz, H (1991) Glass: Nature, Structure and Properties. Springer-Verlag.

[4] Wintour, N. (2015) The glass industry: Recent trends and changes in working conditions and employment relations. International Labour Office (ILO) Cataloguing in Publication DataGeneva.

[5] Scott, C and Dan, S. (2019) Glass Innovation in Grocery Store. American Ceramic Society Bulletin, Vol. 98, No. 5.

[6] Rawson, H. (1980) Properties and Application of Glass, Elsevier S.

[7] Hollands, L (1998) The Glass to Metal Interface during Container Forming Processes. A thesis presented at Centre for Glass ResearchUniversity of Sheffield.

[8] Joan L. P (2002) Glass Industry of the Future: Energy and Environmental Profile of the U.S. Glass Industry IncorporatedColumbia, Maryland.

[9] Iguda, S. L (2011) Road Situationand the Development of Katsina State, Nigeria JORIND (9)

[10] Ileoje, N.P (2004)-A New Geography of Nigeria. Fifth Education, Lagos: Longman Nigeria Plc.

[11] Nigerian Metrological Agency (NIMET, 2010). Summary of climatic conditions of Katsina from $2002-2012$. 